\title{
The meshing of timing belt teeth in pulley grooves
}

\author{
T H C Childs ${ }^{1}$, K W Dalgarno ${ }^{1}$, M H Hojjati ${ }^{1}$, M J Tutt ${ }^{1}$ and A J Day ${ }^{2}$ \\ ${ }^{1}$ Department of Mechanical Engineering, University of Leeds \\ ${ }^{2}$ University of Bradford
}

\begin{abstract}
The work described here has been carried out to obtain a better understanding of the tooth root cracking failure mode of timing belts. Previous work has demonstrated the close dependence of this on the tooth deflections of fully meshed teeth, generated by torque transmission, but has not considered the additional distortions generated in the partially meshed conditions at entry to and exit from a pulley groove. Approximate compatibility and constitutive equations are combined with a rigorous consideration of tooth equilibrium in partial meshing to show how bending moments are generated at both exit from a driven pulley and entry to a driving pulley. Experimentally determined belt lives correlate very well with a combined measure of fully meshed tooth strain and strain due to bending at entry or exit. The analysis also shows that this strain measure reduces with increasing belt tooth stiffness, confirming the importance of a high tooth stiffness for a long belt life. Tooth force variations through the partial meshing cycle have also been predicted and compared with measurements obtained from a special strain gauge instrumented pulley. A greater pulley rotation than is predicted is required for a belt tooth to seat in a pulley groove. There is room for improvement in the modelling.
\end{abstract}

Keywords: power transmission, timing belts, failure analysis, tooth root cracking

\section{NOTATION}

$F_{i} \quad$ land friction force at fully meshed pitch $i$

$F, N \quad$ tooth friction and normal contact load

$K_{\mathrm{t}} \quad$ fully meshed belt tooth stiffness

$K_{\mathrm{p}} \quad$ tooth stiffness in the partial meshing model

$K_{\mathrm{b}} \quad$ belt cord stiffness

$N_{\mathrm{f}} \quad$ number of fully meshed teeth

$P_{\mathrm{b}} \quad$ unstretched belt pitch length

$P_{\mathrm{p}} \quad$ pulley pitch measured at the cord line

$Q_{i} \quad$ circumferential tooth load at fully meshed pitch $i$

$R_{\mathrm{p}}, \mathrm{d} R_{\mathrm{p}} \quad$ pulley radius and pitch line differential

$R_{\mathrm{c}} \quad$ radius at the cord line

$T_{\mathrm{G}} \quad$ cord tension at $\mathrm{G}$ (see Fig. 3a)

$T_{i}, T_{i}^{\prime} \quad$ belt cord tensions at pitch $i$

$T_{\mathrm{s}} \quad$ slack side tension

$T_{\mathrm{t}} \quad$ tight side tension

$\gamma \quad$ friction angle

$\theta_{\mathrm{a}} \quad$ geometric angle of wrap

$\theta_{\mathrm{e}, \mathrm{f}} \quad$ angular extent of land contacts in partially meshed tooth model

$\theta_{\mathrm{g}} \quad$ angular extent of a fully meshed tooth-groove contact

$\theta_{\mathrm{h}, \mathrm{i}, \mathrm{j}, \mathrm{k}} \quad$ hinge angles in partially meshed tooth model $\theta_{1}$

$\theta_{\mathrm{n}, i}$

$\theta_{\mathrm{p}}$

$\theta_{\mathrm{r}}$ (see Fig. 3)

$\theta_{\mathrm{s}} \quad$ angular position of slack side partially meshing

groove

$\theta_{\mathrm{t}} \quad$ angular position of tight side partially meshing

$\theta_{\mathrm{u}, \mathrm{v}}$

$\lambda_{i}$

$\mu$

angular extent of a fully meshed land contact pulley surface outward normal direction in partial meshing model

angular extent of one pitch on pulley

angular variable in partially meshed tooth model

groove tooth seating angles in the tight and slack sides (see Fig. 3)

tooth deflection at fully meshed pitch $i$

belt/pulley sliding friction coefficient

\section{INTRODUCTION}

Timing belts, originally developed with trapezoidal tooth forms for synchronous motion transmission, are now developed with curvilinear tooth forms to the stage that their torque transmitting capacity matches that of vee belts of the same size (1). Their service life may be limited by wearing away of the protective fabric that covers the rubber teeth and belt land regions, or by failure of the fabric at the tooth roots, or by other mechanisms such as separation of the fabric cover from the belt or failure of the tensile loadcarrying cords or by cracking of the back cover (2-4). This

The MS was received on 21 September 1995 and was accepted for publication on 31 May 1996. 
paper reports a study of curvilinear belt tooth meshing with pulley grooves, to gain a better understanding of the tooth root failure mode: this is the common life limiting mode for automotive cam shaft drive belts.

In earlier work on tooth root failure (5), in agreement with studies on trapezoidal toothed belts (6), log-linear laws have been established between belt life and torque transmission that can be understood more fundamentally as log-linear relations between life and the tangential component of belt tooth-pulley groove contact load. More recently, by carrying out life tests on a range of belts with different tooth stiffness, it has been established that the fundamental relation is between life and the tooth deflection caused by loading, i.e. it is the distortion of the cover in the root region that determines failure (4). However, if tooth loading or deflection is calculated from models that consider the mechanics only of the fully meshed state, it is found that quantitatively different life laws apply to failures at the driven and driving contact roots: tooth loads/deflections generated on a driving pulley can be 1.5 to 2 times larger than those generated on a driven pulley for any given belt life (in the range 1-100 million tooth loading cycles) (7). This observation is consistent with the speculation that additional root distortions occur when a belt tooth comes into mesh with and leaves a pulley groove, and that these are more damaging on a driven than a driving pulley. In the work of reference (7) the largest fully meshed tooth loads occurred in driven pulley exit and driver pulley entry conditions. It is plausible that at driven pulley exit additional tensile strains are generated at tooth roots when a tooth is pulled out of a pulley groove and that these are suppressed at driver entry where the belt tooth is being pushed into a pulley groove.

In this paper, a simplified model of belt meshing and unmeshing is introduced to address these speculations. A belt's tooth is joined to its adjacent lands by frictionless hinges and the tooth contact load with a pulley groove is described by a simple foundation model in which contact pressure at a point depends only on the tooth displacement there (8). Tooth force and moment equations are solved to predict tooth loadings and articulations. Loadings are compared with low-speed experimental measurements. These considerations of entry and exit lead to a better understanding of the life observations (7) but a full explanation requires a better model still.

\section{THEORY}

\subsection{Meshing overview}

Figure 1 introduces the belt-pulley contact problem to be modelled. A geometrical angle of wrap $\theta_{\mathrm{a}}$ is defined. It is the angle between the normals to the lines of action of the tight and slack side belt tension forces $T_{\mathrm{t}}$ and $T_{\mathrm{s}}$. Within

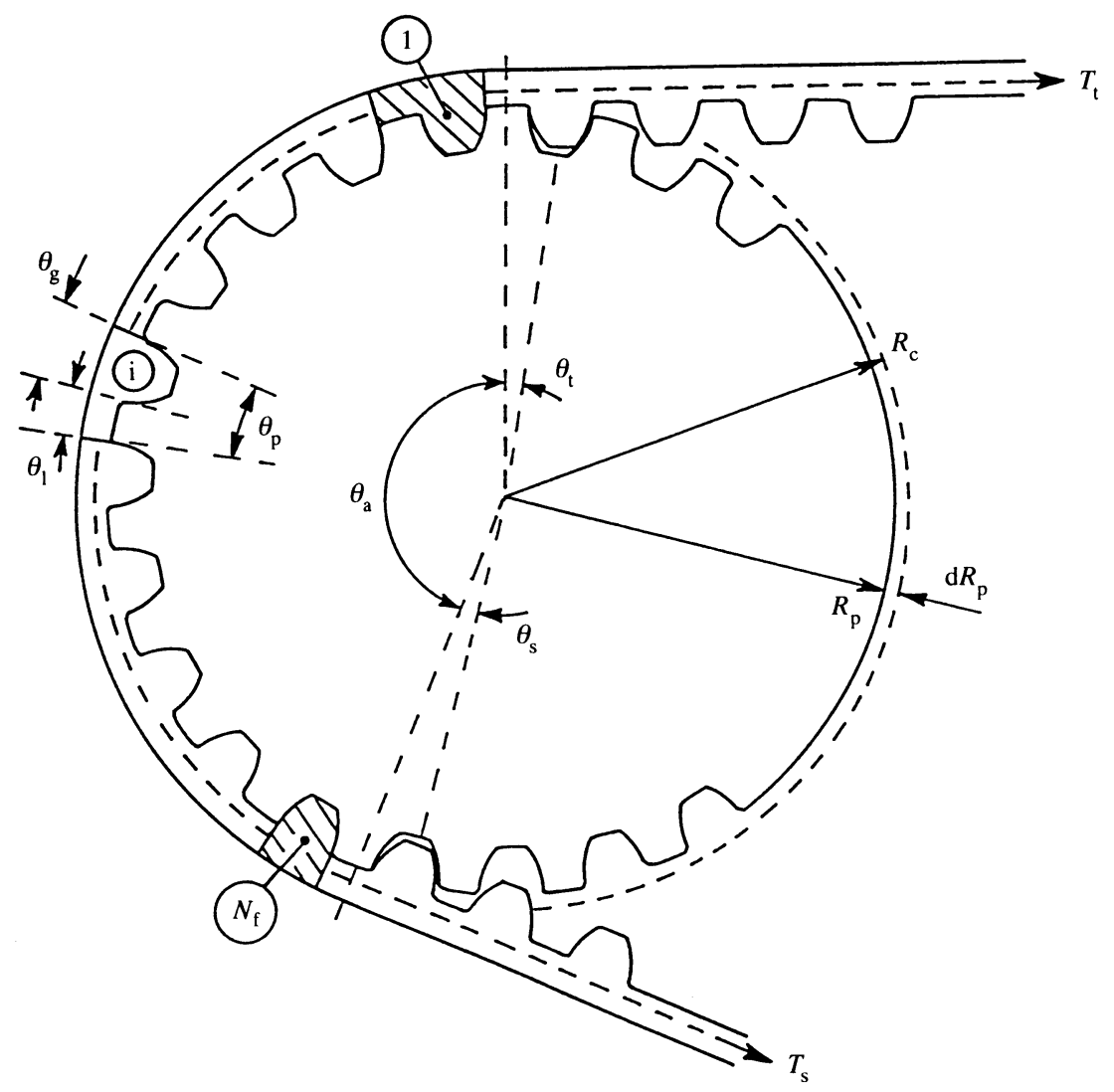

Fig. 1 Belt and pulley meshing overview 
the angle of wrap there are $N_{\mathrm{f}}$ belt teeth/pulley grooves fully meshed. Outside the angle of wrap there are additional teeth/groove contacts in partial mesh.

A fully meshed tooth, for example tooth $\mathrm{i}$ in Fig. 1, subtends an angle $\theta_{\mathrm{p}}$ at the centre of the pulley, related to the number of teeth $N_{\mathrm{t}}$ on the pulley by

$$
\theta_{\mathrm{p}}=\frac{2 \pi}{N_{\mathrm{t}}}
$$

A part $\theta_{1}$ of $\theta_{\mathrm{p}}$ is taken up by land contact and a part $\theta_{\mathrm{g}}$ by tooth-groove contact. In this paper it is assumed, as in Fig. 1 , that a pulley groove becomes a fully meshed contact once its centre line is within the angle of wrap by more than $\theta_{\mathrm{g}} / 2$. It is also assumed that at each of the tight and slack sides there is only one partially meshed contact. The angular position of the partially meshing pulley groove at the tight side is described by the angular position $\theta_{\mathrm{t}}$ of its centre line; and likewise, $\theta_{\mathrm{s}}$ describes the angular position of the slack side partially meshing tooth. $\theta_{\mathrm{t}}$ and $\theta_{\mathrm{s}}$ vary as the pulley rotates but they are related by the geometrical requirements

$$
\theta_{\mathrm{t}}+\theta_{\mathrm{a}}+\theta_{\mathrm{s}}=\left(N_{\mathrm{f}}+1\right) \theta_{\mathrm{p}}, \quad-\theta_{\mathrm{g}} / 2 \leqslant \theta_{\mathrm{t}}, \theta_{\mathrm{s}} \leqslant \theta_{\mathrm{l}}+\frac{\theta_{\mathrm{g}}}{2}
$$

Equation (2) serves to determine $N_{\mathrm{f}}$ and $\theta_{\mathrm{s}}$ for any angular position of the pulley, defined by $\theta_{\mathrm{t}}$. It also constrains meshing and unmeshing to occur within one pitch of pulley rotation. This restriction, the better the higher the belt tension and the smaller the pulley diameter, is discussed in Section 5.

\subsection{Fully meshed tooth mechanics}

The fully meshed modelling has been published before (5) but is summarized here for convenience of later use. By convention, as in Fig. 1, the fully meshed belt pitches are labelled 1 to $N_{\mathrm{f}}$, from the tight to the slack side; and the land associated with a particular tooth is anti-clockwise from the tooth. Figure $2 \mathrm{a}$ is a detail of the forces on the general pitch $i$. It shows the belt cord tension changing from $\mathrm{T}_{i}$ at the boundary with pitch $(i-1)$ to $\mathrm{T}_{i+1}$, with an intermediate value $T_{i}^{\prime}$ at the junction between the tooth and land. It also shows the circumferential component $\mathrm{Q}_{i}$ of the tooth-groove contact load and the land friction force $F_{i}$. Circumferential force equilibrium gives

$$
T_{i}^{\prime}=T_{i}-Q_{i} \quad \text { and } \quad T_{i+1}=T_{i}^{\prime}-F_{i}
$$

and the capstan formula (assuming that there is sliding between the belt and pulley land) gives

$$
F_{i}=T_{i}^{\prime}\left[1-\exp \left(-\delta \mu \theta_{1}\right)\right]
$$

where $\mu$ is the land sliding friction coefficient and $\delta= \pm 1$ depending on the direction of sliding, explained later.

Figure $2 \mathrm{~b}$ concerns the compatibility of the stretching and displacement of the belt pitch within the pulley pitch. It places a belt pitch, of initial length $P_{\mathrm{b}}$ at the cord line but stretched by tension to $P_{\mathrm{b}}+\mathrm{d} P_{\mathrm{b}}$, on to the pulley pitch, of length $P_{\mathrm{p}}$ at the cord line. It shows a displacement $\lambda_{i}$ at one end, that gives rise to the tooth loading $Q_{i}$, and a possibly different displacement $\lambda_{i+1}$ at the other end. Compatibility of meshing requires

$$
\lambda_{i+1}=\lambda_{i}+\left(P_{\mathrm{p}}-P_{\mathrm{b}}\right)-\left(\mathrm{d} P_{\mathrm{b}}\right)_{i}
$$

where, for a pulley of cord line radius $R_{\mathrm{c}}\left(R_{\mathrm{c}}=R_{\mathrm{p}}+\right.$ the pitch line differential $\mathrm{d} R_{\mathrm{p}}$ )

$$
P_{\mathrm{p}}=R_{\mathrm{c}} \theta_{\mathrm{p}}
$$

The belt tooth is supposed to be linearly elastic, so that a tooth stiffness $K_{\mathrm{t}}$ is defined by

$$
Q_{i}=K_{\mathrm{t}} \lambda_{i}
$$

The cord is also assumed linearly elastic, so that a uniform tension $T$ is related to the stretch of one pitch by

$$
T=K_{\mathrm{b}} \mathrm{d} P_{\mathrm{b}}
$$

In fact (Fig. 2a) a belt pitch is not under uniform tension. If tension is assumed to vary linearly from $T_{\mathrm{i}}$ to $T_{i}^{\prime}$ over the

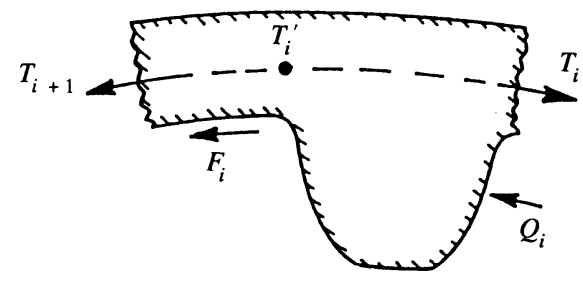

(a)

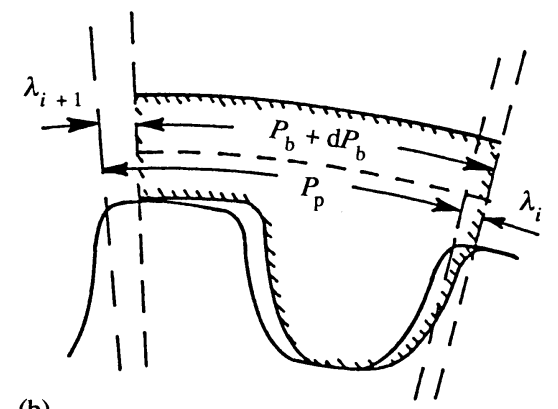

(b)

Fig. 2 (a) Forces on and (b) compatibility of meshing of a fully meshed belt pitch 
tooth and then as required by the capstan formula over the land it can be shown that $(\mathbf{4 , 5})$

$$
\left(\mathrm{d} P_{\mathrm{b}}\right)_{i}=\frac{P_{\mathrm{p}}}{P_{\mathrm{b}} K_{\mathrm{b}}}\left\{\frac{\theta_{\mathrm{g}}}{\theta_{\mathrm{p}}} \frac{\left(T_{i}+T_{i}^{\prime}\right)}{2}+\frac{T_{i}^{\prime} \delta}{\mu \theta_{\mathrm{p}}}\left[1-\exp \left(-\delta \mu \theta_{1}\right)\right]\right\}
$$

where $\delta=+1$ on a driven pulley and -1 on a driving pulley, if $T \geqslant K_{\mathrm{b}}\left(P_{\mathrm{p}}-P_{\mathrm{b}}\right)$; and has the opposite sign otherwise.

If $T_{\mathrm{i}}$ and $\lambda_{\mathrm{i}}$ are given, the system of equations (3) to (9) enables $T_{i+1}$ and $\lambda_{i+1}$ to be calculated for given belt properties $K_{\mathrm{b}}, K_{\mathrm{t}}$ and $\mu$, pulley radius $R_{\mathrm{p}}$ and pitch line differential $\mathrm{d} R_{\mathrm{p}}$, and pitch difference $\left(P_{\mathrm{p}}-P_{\mathrm{b}}\right)$. In the context of this paper, repeated application of equations (3) to (9) enable $\lambda$ and $\mathrm{T}^{\prime}$ at the last full mesh tooth $N_{\mathrm{f}}$ to be calculated from $\lambda_{1}$ and $T_{1}$ at the first full meshed tooth. Values of $\lambda_{1}$ and $T_{1}$, and $\lambda$ and $T^{\prime}$ at the last full mesh tooth act as boundary conditions to the partial meshing analysis.

\subsection{Partially meshed tooth mechanics}

Figure 3a represents an approximation to the geometry of a partially meshed tooth at the tight side. A part FG of the cord in the belt land, subtending an angle $\theta_{\mathrm{f}}$ at the pulley centre, is wrapped round the pulley. The part GH is assumed to be straight, in the direction of the tangent to the pulley at G. The back of the belt tooth, HI, is also assumed to be straight. It is further assumed, as an approximation,

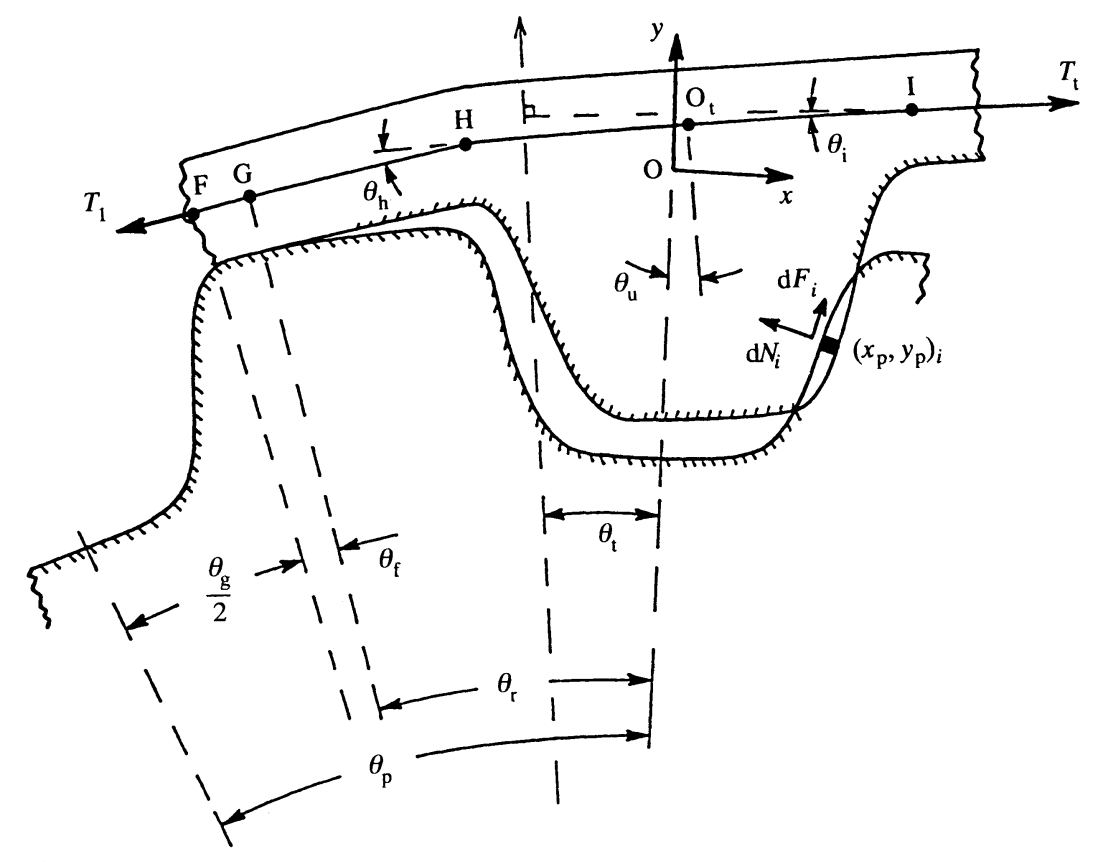

(a)

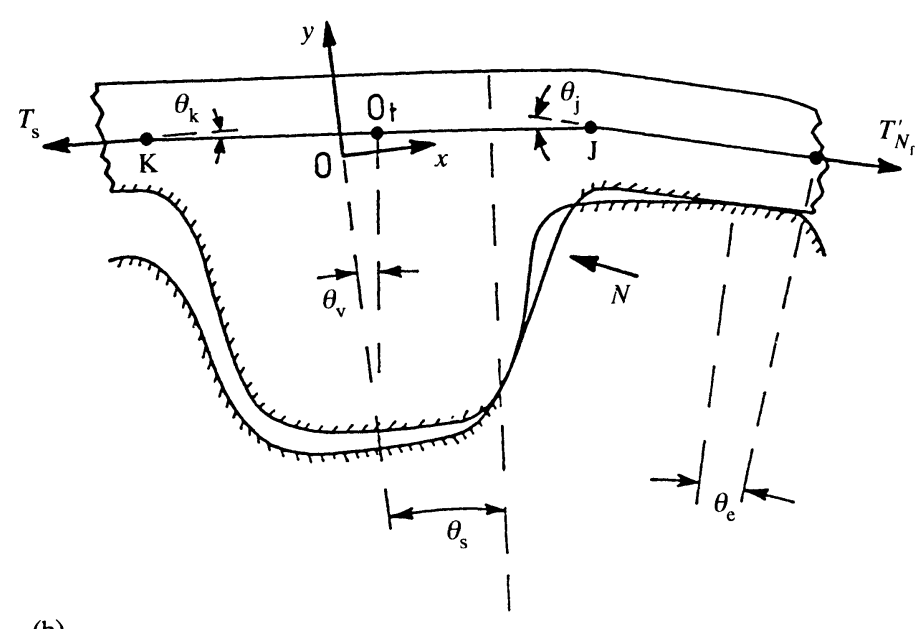

(b)

Fig. 3 (a) A tight side and (b) a slack side partially meshed tooth 
that there is a frictionless hinge at $\mathrm{H}$, so that the direction of $\mathrm{HI}$ can differ from that of GH by $\theta_{\mathrm{h}}$. Similarly a hinge at I allows the direction of HI to differ from that of $T_{\mathrm{t}}$ by $\theta_{\mathrm{i}}$. With these simplifying assumptions of the cord path, and knowledge of the pulley groove and belt tooth profiles, the interference between the belt tooth and pulley groove can be calculated.

Figure 3a also shows an element $\mathrm{d} N_{i}$ and $\mathrm{d} F_{i}$ of the distributed contact force between the belt tooth and pulley groove. If it is assumed that this is proportional to the interference, three equilibrium equations (two force and one moment) can be developed from the geometry equations. Similarly, three equilibrium equations can be set up for the slack side (Fig. 3b), involving hinge angles $\theta_{\mathrm{j}}$ and $\theta_{\mathrm{k}}$. The following paragraphs show how six equilibrium equations can be set up for the six unknowns $\lambda_{1}, T_{1}, \theta_{\mathrm{h}}, \theta_{\mathrm{i}}$, $\theta_{\mathrm{j}}$ and $\theta_{\mathrm{k}}$, and solved to determine the belt path and loadings.

It is chosen to describe the pulley groove and belt tooth profiles in an $x-y$ coordinate system with origin at the intersection of the centre line of the partially meshing pulley groove and the pulley pitch circle of radius $R_{\mathrm{c}}$, as illustrated in Fig. 3a and b. $y$ is the outward radial direction and $x$ the circumferential direction as shown. This choice is made because the belt tooth centre $\mathrm{O}_{t}$ on the cord line should settle close to the origin of this coordinate system in a fully meshed state. First of all the position of $\mathrm{O}_{t}$ on the tight side is determined by following the path of the belt cord from the point $\mathrm{G}$ :

$$
\begin{aligned}
& x_{\mathrm{O}_{\mathrm{t}}}=-R_{\mathrm{c}} \sin \theta_{\mathrm{r}}+l_{\mathrm{GH}} \cos \theta_{\mathrm{r}}+\frac{l_{\mathrm{HI}}}{2} \cos \left(\theta_{\mathrm{r}}-\theta_{\mathrm{h}}\right) \\
& y_{\mathrm{O}_{\mathrm{t}}}=R_{\mathrm{c}}\left(\cos \theta_{\mathrm{r}}-1\right)+l_{\mathrm{GH}} \sin \theta_{\mathrm{r}}+\frac{l_{\mathrm{HI}}}{2} \sin \left(\theta_{\mathrm{r}}-\theta_{\mathrm{h}}\right)
\end{aligned}
$$

where, from loop equations

$$
\begin{aligned}
& \theta_{\mathrm{r}}=\theta_{\mathrm{p}}-\frac{\theta_{\mathrm{g}}}{2}-\theta_{\mathrm{f}} \\
& \theta_{\mathrm{f}}=\theta_{\mathrm{p}}-\theta_{\mathrm{t}}-\frac{\theta_{\mathrm{g}}}{2}-\theta_{\mathrm{i}}-\theta_{\mathrm{h}}
\end{aligned}
$$

and the lengths $l_{\mathrm{GH}}$ and $l_{\mathrm{HI}}$ take into account the stretching of the cord as described in Appendix 1.

The inclination $\theta_{\mathrm{u}}$ of the tooth to the $y$ axis is also determined:

$$
\theta_{\mathrm{u}}=\theta_{\mathrm{i}}+\theta_{\mathrm{t}}
$$

Then a transformation of the belt tooth profile from a coordinate system fixed in the tooth to the $x-y$ system fixed in the pulley can be made and an interference assessment carried out, as described in Appendix 2. If an element of the pulley surface at $\left(x_{\mathrm{p}}, y_{\mathrm{p}}\right)_{i}$ is associated with an overlap area $\delta A_{i}$ with the belt (as described in Appendix
2) contact element normal and friction forces $\delta N_{i}$ and $\delta F_{i}$ are deduced and summed and resolved over the whole contact to produce total tooth contact forces and moments $F_{x}, F_{y}$ and $M$ :

$$
\begin{aligned}
\delta N_{i} & =K_{\mathrm{p}} \delta A_{i} ; \quad \delta F_{i}=\mu_{i}^{*} \delta N_{i} \\
F_{x} & =\sum_{i=1 \mathrm{to} n} \delta N_{i}\left(\cos \theta_{\mathrm{n}, i} \pm \mu_{i}^{*} \sin \theta_{\mathrm{n}, \mathrm{i}}\right) \\
F_{y} & =\sum_{i=1 \mathrm{to} n} \delta N_{i}\left(\sin \theta_{\mathrm{n}, i} \pm \mu_{i}^{*} \cos \theta_{\mathrm{n}, \mathrm{i}}\right) \\
M & =\sum_{i=1 \mathrm{to} n} \delta N_{i}\left[\left(\cos \theta_{\mathrm{n}, i} \pm \mu_{i}^{*} \sin \theta_{\mathrm{n}, \mathrm{i}}\right)\left(y_{\mathrm{p}, \mathrm{i}}-y_{\mathrm{O}_{\mathrm{t}}}\right)\right. \\
& \left.-\left(\sin \theta_{\mathrm{n}, i} \pm \mu_{i}^{*} \cos \theta_{\mathrm{n}, \mathrm{i}}\right)\left(x_{\mathrm{p}, \mathrm{i}}-x_{\mathrm{O}_{\mathrm{t}}}\right)\right]
\end{aligned}
$$

where $K_{\mathrm{p}}$ is a tooth element stiffness constant, $\theta_{\mathrm{n}, i}$ is the direction of the force $\delta N_{i}, \pm$ depends on the direction of sliding of the belt element in the pulley groove and $\mu_{i}^{*}$ is an effective friction coefficient, $\leqslant \mu$. The direction of sliding and the size of $\mu_{i}^{*}$ are considered further in Section 2.4, as is an appropriate size for $K_{\mathrm{p}}$.

Finally the three tight side tooth equilibrium equations are set up

$$
\begin{aligned}
& T_{\mathrm{G}} \cos \theta_{\mathrm{h}}-T_{\mathrm{t}} \cos \theta_{\mathrm{i}}-F_{x} \cos \theta_{\mathrm{u}}-F_{y} \sin \theta_{\mathrm{u}}=0 \\
& T_{\mathrm{G}} \sin \theta_{\mathrm{h}}+T_{\mathrm{t}} \sin \theta_{\mathrm{i}}+F_{x} \sin \theta_{\mathrm{u}}-F_{y} \cos \theta_{\mathrm{u}}=0 \\
& M+\left(T_{\mathrm{t}} \sin \theta_{\mathrm{i}}-T_{\mathrm{G}} \sin \theta_{\mathrm{h}}\right) \frac{l_{\mathrm{HI}}}{2}=0
\end{aligned}
$$

These, with the equivalent three slack side equations, incorporating the full mesh equations (Section 2.2) that connect the tight and slack side partially meshing teeth conditions, form the system of six equations that determine $\lambda_{1}, T_{1}, \theta_{\mathrm{h}}, \theta_{\mathrm{i}}, \theta_{\mathrm{j}}$ and $\theta_{\mathrm{k}}$.

\subsection{Calculation procedure}

Inputs to the calculation are the operating conditions of tight and slack side belt tension (obtained from the transmitted torque and total belt tension), the angle of wrap on the pulley and the number of teeth on the pulley; belt geometry conditions of belt pitch length, the difference between the pulley and belt pitch measured at the cord line and the pitch line differential (measured between the cord line and the pulley surface) and the groove and tooth profiles; and the belt stiffness and friction properties. It is further specified whether the calculation is to be for a driving or driven pulley: in the full mesh part of the contact this is needed to fix the direction of the land friction forces [equations (4) and (9), $\delta= \pm 1$ )]; in the partial mesh regions, it determines whether the instantaneous views, for 
example in Fig. 3, are to be regarded as views of teeth entering or leaving contact. Figure 3 represents driven pulley contacts if the pulley is imagined as rotating clockwise and driving pulley contacts if anti-clockwise.

The calculation proceeds by selecting an initial value $\theta_{\mathrm{t}}$ of the pulley angular position, developing the six tooth equilibrium equations (Section 2.3) and solving for the six unknowns using a minimization of residuals technique, the Powell optimization routine to be found in the National Algorithm (NAG) library (9). The method requires an initial guess: $T_{1}$ is initially taken to be $T_{\mathrm{t}}$ and the other five variables are set to zero. Subsequently, $\theta_{\mathrm{t}}$ is incremented and the solution procedure is repeated, with the solution from the previous step as the initial guess.

This procedure of following the pulley rotation is not only efficient with respect to choosing the initial guess, it is essential for determining the size and direction of the contact friction forces $\left[\delta F_{i}\right.$ in equation (13)]. The direction of motion of each element on the belt tooth surface is tracked, regarding the tooth as a rigid body: that is to say motion associated with the tooth contact deformation is neglected. The direction is calculated from the motion of the tooth centre plus rotation about the centre and requires the position of the tooth centre and the tooth angular orientation from the previous increment to be known. At each pulley contact element, $\left(x_{\mathrm{p}}, y_{\mathrm{p}}\right)_{i}$ in Fig. 3 , the direction of motion of the belt tooth relative to the pulley normal, $\gamma_{i}^{*}$, is obtained. It is interpreted as a friction angle: in equation (13)

$$
\begin{array}{ll}
\mu_{i}^{*}=\tan \gamma_{i}^{*} & \text { if } \tan \gamma_{i}^{*} \leqslant \mu \\
\mu_{i}^{*}=\mu & \text { if } \tan \gamma_{i}^{*} \geqslant \mu
\end{array}
$$

and the direction of the friction force opposes the projection on to the contact plane of the direction of motion.

Meshing and unmeshing calculations for driving and driven pulleys have been carried out for curvilinear toothed belts with the profile known as $\mathrm{HTD}^{\dagger}(\mathbf{1 0})$ and are reported in Section 4. Table 1 lists the input data around which the main calculations have been performed. A further set of calculations has been carried out for an outof-specification pulley with $P_{\mathrm{p}}-P_{\mathrm{b}}=0.029 \mathrm{~mm}$, to make

Table 1 Input conditions for a $19.75 \mathrm{~mm}$ wide HTD1 belt running on a HTD pulley

\begin{tabular}{lcl}
\hline $\begin{array}{c}\text { Operating } \\
\text { conditions }\end{array}$ & Belt pitch conditions & Belt material properties \\
\hline$N_{\mathrm{t}}=19$ & $P_{\mathrm{b}}=9.519 \mathrm{~mm}$ & $K_{\mathrm{b}}=40000 \mathrm{~N} / \mathrm{mm}$ \\
$\theta_{\mathrm{a}}=180^{\circ}$ & $P_{\mathrm{p}}-P_{\mathrm{b}}=0.006-0.014 \mathrm{~mm}$ & $K_{\mathrm{t}}=300 \mathrm{~N} / \mathrm{mm}$ \\
$T_{\mathrm{t}}=750$ to & & $K_{\mathrm{p}}=90-180 \mathrm{~N} / \mathrm{mm}^{2}$ \\
$1500 \mathrm{~N}$ & & \\
$T_{\mathrm{s}}=0-750 \mathrm{~N}$ & $\mathrm{~d} R_{\mathrm{p}}=0.686 \mathrm{~mm}$ & $\mu=0.2$ \\
\hline
\end{tabular}

${ }^{\dagger}$ HTD is a registered trade name of the Gates Rubber Company Limited. a comparison with experiments also reported in Section 4 . The belt material properties (Table 1) correspond to those relevant to the life studies described in Section 1. They are all measured values except for $K_{\mathrm{p}}$. When a tooth becomes fully meshed, its total overlap area, as defined in the partial mesh calculation, becomes the product of groove depth and tooth deflection $\lambda$. From considering expressions for tooth load from the fully and partially meshed models, one would expect a relation between $K_{\mathrm{p}}$ and $K_{\mathrm{t}}$

$$
K_{\mathrm{p}} \propto \frac{K_{\mathrm{t}}}{\text { groove depth }}
$$

with the constant of proportionality depending on the direction of the resultant force in the partially meshed model. The range of values for $K_{\mathrm{p}}$ in Table 1 corresponds to a constant of proportionality from 1 to 2 .

\subsection{Tooth root failure considerations and sensitivity calculations}

Two simple measures of tooth strain may be identified during partial meshing. The fully meshed tooth deflection $\lambda$ has associated with it a shear strain $\lambda / t_{\mathrm{d}}$ averaged over the tooth, where $t_{\mathrm{d}}$ is the tooth depth. The moment about the tooth centre, $M$, of the contact forces between the pulley groove and the belt tooth causes bending strains. Treating the tooth as a simple beam gives a bending strain at the tooth root of $M y /(E I)$ where $y$ is half the tooth width $t_{\mathrm{w}}$. In practice $t_{\mathrm{w}} \approx 2 t_{\mathrm{d}}$. If $I$ is taken as $w t_{\mathrm{w}}^{3} / 12$ and $E$ as $K_{\mathrm{t}} / w$, where $w$ is the belt width, an expression for bending strain is $\approx 6 M /\left(K_{\mathrm{t}} t_{\mathrm{w}}^{2}\right)$. It will be shown in Section 4 that tooth root cracking belt failures correlate better with a simple addition of the two strains

$$
\Psi=\frac{\lambda}{t_{\mathrm{d}}}+\frac{6 M}{K_{\mathrm{t}} t_{\mathrm{w}}^{2}}
$$

than with either strain measure separately. The sensitivity of $\Psi$ to belt operating conditions and changes of belt pitch geometry and material properties around the actual values in Table 1 will be reported.

\section{EXPERIMENTATION}

A low-speed belt torque transmission rig has been built to enable the build up and decay of contact forces to be measured as a belt tooth enters and leaves mesh with a pulley groove (Fig. 4). Torque is transmitted between pulleys mounted on two parallel shafts, one driven and one braked by a $0.37 \mathrm{~kW}$ motor. The system is designed for both shafts to rotate at the same rate (equal sized pulleys) and variable speed gearing allows rotation speeds from 1 to $20 \mathrm{r} / \mathrm{min}$. Torque is measured by calibrated strain gauges mounted directly on the parallel shafts (torque loss can be calculated from the difference in torque on the driving and 


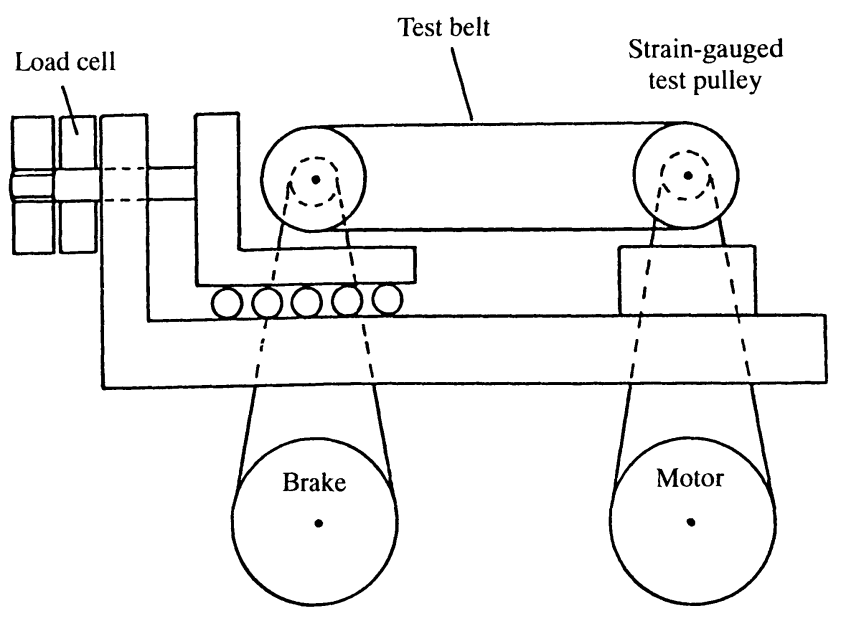

Fig. 4 A schematic view of the low-speed belt test rig

braked shaft). One of the shaft and pulley units is mounted on a roller bearing slideway to allow belt tensioning to be controlled by pulling on the unit. Total belt tension $\left(T_{\mathrm{t}}+T_{\mathrm{s}}\right)$ is measured by a load cell in the load line.

The circumferential and radial components of contact load are measured on one groove of a specially instrumented pulley, shown in Fig. 5a. Spark erosion has been used to carve away the carcass of a pulley, to leave one part of a pitch supported on two sets of struts oriented at $\pm 45^{\circ}$ to the radial direction, as shown. Strain gauges mounted on the struts, with dummy gauges mounted elsewhere on the pulley hub, form two full bridge circuits for measuring the two components of force in the strut directions as the pulley rotates. Calibration of the system with static loads applied at point $\mathrm{A}$ in Fig. 5a, coupled with force resolution, allows the circumferential and radial loads on the instrumented section of the pulley to be determined. The output from the two bridge systems is fed to an amplifier and then directly to a digital oscilloscope. The quality of output is illustrated by the tracing of the direct printout from the oscilloscope shown in Fig. 5b. It shows the variation of signal (in volts) with pulley rotation from each of the bridges. Signal noise is virtually non-existent. The limit to the accuracy of interpreting the output is a variation of zero level from entry to exit (start to finish) which is believed to be caused by varying pulley hub distortion as the struts rotate through the loaded portion of the pulley.

The struts have been created on a 19-tooth HTD pulley. Their small size (forced by the available space) made both their accurate spark erosion and placing and wiring the strain gauges extremely difficult. At the time the construction was planned, it was decided that the forces on one half of the pulley groove and an adjacent pulley land would be measured, as shown by the positioning of the cuts in Fig. $5 \mathrm{a}$. With hindsight it would have been preferred to include the whole of the pulley groove, but the effort to instrument a second pulley could not be justified. However, by reversing the direction of pulley rotation and at the same time switching the driving shaft to be the brake (and vice versa), the one pulley can be used to study meshing and unmeshing in both driving and driven conditions. Finally it should be recorded that the instrumented pulley was made from wrought material [the commercial pulleys used in belt tooth root cracking life tests $(\mathbf{4}, \mathbf{6 , 7})$ were sintered]. The pulley that was obtained was slightly oversize, so that $P_{\mathrm{p}}-P_{\mathrm{b}}$ was $0.029 \mathrm{~mm}$.

\section{OBSERVATIONS}

\subsection{Load observations at low speeds}

Figure 6 presents a typical result from the low-speed pulley rig. It shows the variation of tangential and radial load on the strain-gauged pulley tooth and land from entry to exit for (a) a driving and (b) a driven pulley, for a torque of $19 \mathrm{Nm}$ and a total belt tension of $1130 \mathrm{~N}$. First of all, the total angular span of contact of $220^{\circ}$ is just over 11.5 pitches, consistent with partial meshing teeth outside the geometrical angle of wrap. At driving entry, over the first

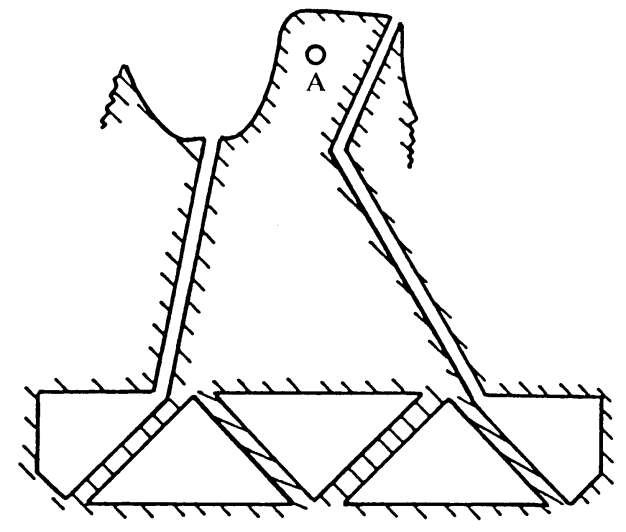

(a)

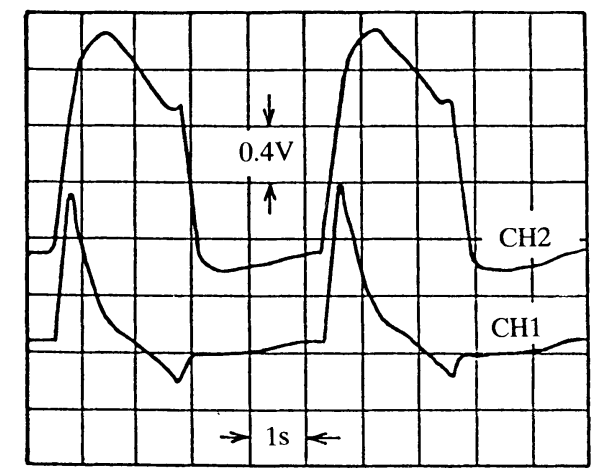

(b)

Fig. 5 (a) The strain-gauged pulley tooth and (b) an example of its output 
(a)

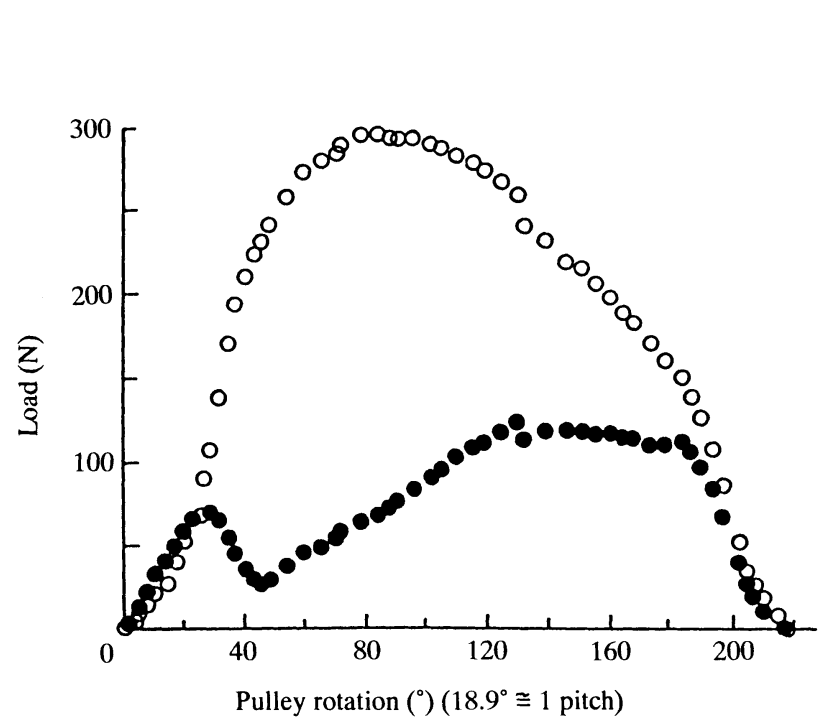

Fig. 6 Measured tangential (•) and radial (○) forces on (a) a driving and (b) a driven pulley $($ torque $=19 \mathrm{Nm}$, total tension $=1130 \mathrm{~N}$ )

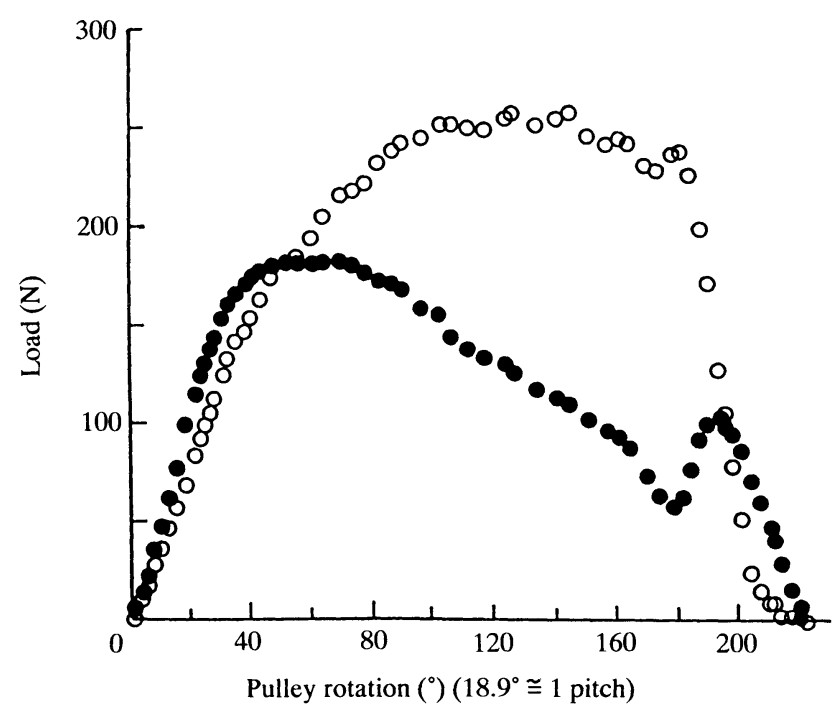

(b) $20^{\circ}$ of contact, the tangential and radial loads rise together, with the tangential load slightly greater than the radial load. At exit, they both fall, but the radial load is slightly greater than the tangential. At driven entry, the tangential load rises and is slightly greater than the radial load; the driven exit is exceptional in that the radial load decreases very much more rapidly than does the tangential load. These features are common to most operating conditions, as is the local maximum in tangential force at driving entry and driven exit. A more comprehensive account of these experiments will be published on another occasion.

\subsection{Computed results and comparisons with experiment}

Figure 7 presents the entry and exit tooth loads calculated from the partial meshing model for the same conditions as in Fig. 6, taking $K_{\mathrm{p}}$ to be $90 \mathrm{~N} / \mathrm{mm}^{2}$ (a sensitivity analysis varying $K_{\mathrm{p}}$ from 90 to $180 \mathrm{~N} / \mathrm{mm}^{2}$ showed small variations of loads with $K_{\mathrm{p}}$, but not large enough to consider further). Force is plotted against pulley rotation. The origin for pulley rotation has been shifted from the theoretical measures $\theta_{\mathrm{t}}$ and $\theta_{\mathrm{s}}$ (Fig. 3) to match the experimental pulley rotation positions when $F_{x}$ and $F_{y}=0$. The theoretical force variations are qualitatively like the experiments: the tangential $F_{x}$ is greater than $F_{y}$ at driving and driven entry; $F_{y}$ is greater than $F_{x}$ at driving exit; $F_{y}$ falls to zero more rapidly than $F_{x}$ at driven exit. The trends in rates of change of forces with pulley rotation are also qualitatively similar between theory and experiment: at driver entry and driven exit the ratios of $F_{x}$ to $F_{y}$ change with pulley rotation. However, there is a quantitative discrepancy. The theory, particularly for driver entry and driven exit, shows seating/unseating to occur over a smaller pulley rotation range than occurs experimentally. This is because the theory forces meshing to occur within one pitch of rotation. It only allows one pitch at entry and one at exit to be in partial mesh. This does not occur experimentally. Experiments show that it can take up to two pitches of rotation to seat a belt tooth and even more in some low-tension driven entry conditions. However, with this exception, the characteristics of relative force variation predicted theoretically are sufficiently in line with experiment to encourage further consideration of theoretical predictions.

Figure 8 shows, for the same conditions as Fig. 7, the hinge angle variations $\theta_{\mathrm{h}}, \theta_{\mathrm{i}}, \theta_{\mathrm{j}}$, and $\theta_{\mathrm{k}}$ (Fig. 3) with pulley rotation. In this case rotation is described by the angular values of $\theta_{\mathrm{t}}$ and $\theta_{\mathrm{s}}$. At driver entry, $\theta_{\mathrm{h}}$ is initially greater than $\theta_{\mathrm{i}}$ but a cross-over occurs as meshing develops. At driven exit, $\theta_{\mathrm{h}}$ and $\theta_{\mathrm{i}}$ have a large difference and $\theta_{\mathrm{i}}$ is even negative for a portion of the unmeshing cycle, as a result of friction forces holding the belt tooth in the pulley groove. At driver exit and driven entry $\theta_{\mathrm{j}}$ and $\theta_{\mathrm{k}}$ are much closer in their values than are $\theta_{\mathrm{h}}$ and $\theta_{\mathrm{i}}$ at driver entry and driven exit. All these hinge angle variations are reflected in different characteristic variations with pulley rotation of the moment of the contact forces between the pulley groove and belt tooth. Figure 9 shows how this moment $M$ varies in the same conditions as in Fig. 8. Because the moment would be expected to be bigger the larger is the fully meshed tooth load $Q$, and $Q$ is different at all four meshing conditions in Fig. 9, $M$ has been divided by $Q$ for better comparability. The most severe moment relative to tooth load occurs at driven exit. At driver entry, the relative moment is less. The least relative moment occurs at driver exit. The condition at driven entry is of intermediate severity between driven exit and driver entry. For both driven exit and driver entry conditions the calculations identify an angular position where a maximum moment occurs. 

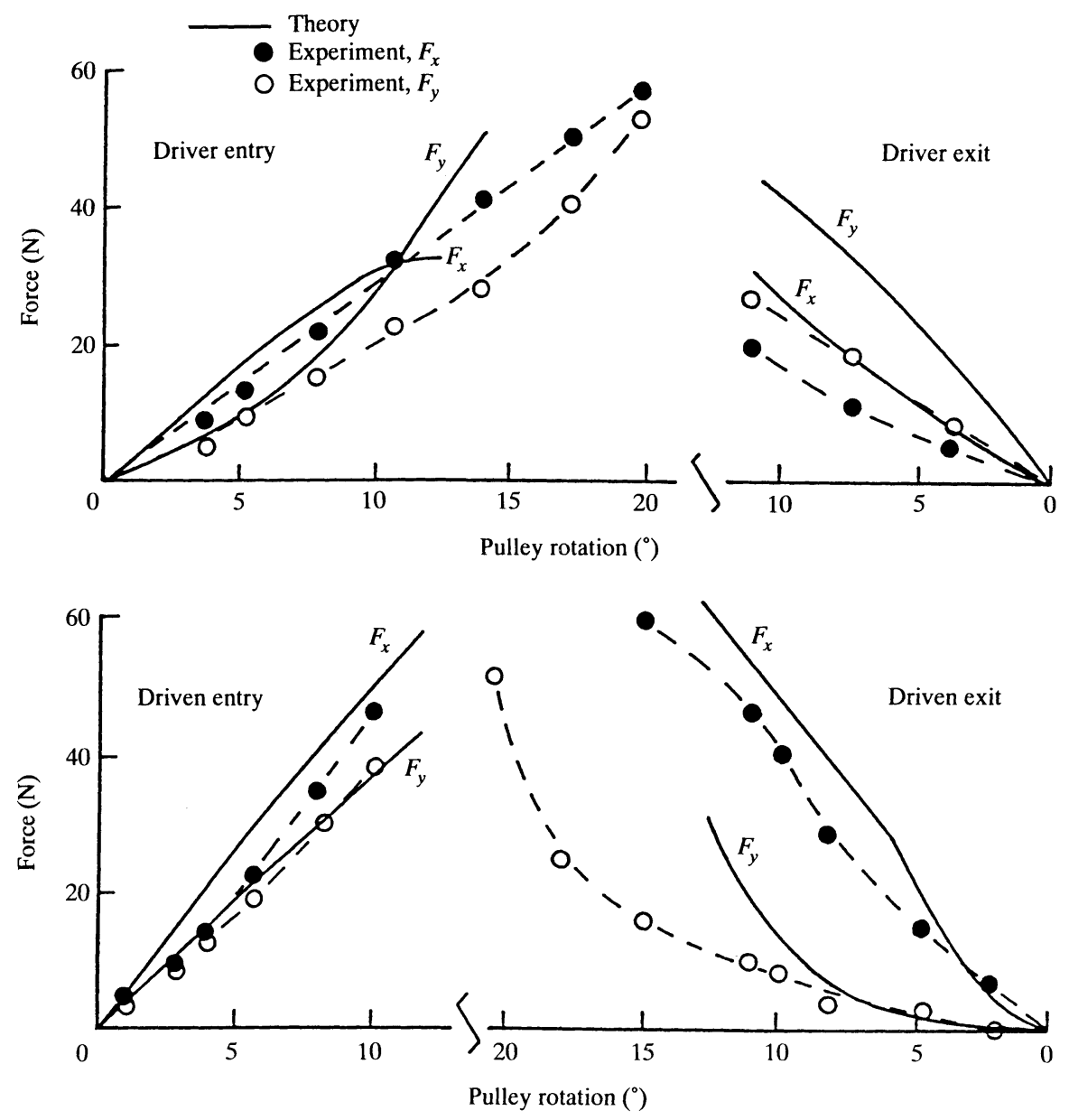

Fig. 7 A comparison between theory and experiment for entry and exit tooth forces for the case of Fig. 6

\subsection{Tooth root failure correlations}

The previous work on belt tooth root cracking failures $(4,6,7)$ found different torque/life relations depending on the angle of wrap of the belt round the pulley (driven or driving) on which failure occurred (Fig. 10a). These were simplified to two separate relations, one for driving entry and the other for driven exit tooth failures, relating fully meshed tooth deflection to life (Fig. 10b). The moment calculation results, Fig. 9, show a more severe bending at driven exit than driver entry. Perhaps a combination of tooth root strains due to fully meshed tooth loading and partial meshing bending would bring together the two failure laws of Fig. 10b. For the belt type to which Fig. 10 refers, equation (17) becomes

$$
\Psi=0.29 \lambda+0.00056 M
$$

with $\lambda$ in $\mathrm{mm}$ and $M$ in $\mathrm{Nmm}$. Figure 10c shows that both driven and driver failures are a single valued function of $\Psi$. $M$ has been taken to be the peak value identified from calculations as in Fig. 9. It suggests that tooth root cracking failures are determined by the combination of bending and deflection at entry to and exit from the pulleys.

\subsection{Sensitivity analyses}

Even though fully meshed tooth deflection $\lambda$ is seen in Fig. 10 not to be a totally unifying parameter for predicting tooth root cracking failures, it is by far the most easy quantity to calculate. If the relation between the more difficult to calculate $\Psi$ and $\lambda$ were known, a practical strategy to predict belt life might calculate $\lambda$ and apply a correction factor to obtain the more fundamental $\Psi$. The dependence of $\Psi$ on $\lambda$ at driven exit and driver entry has been calculated for a range of tight side tensions. At each tension a range of tooth deflections was generated by varying the slack side tension (i.e. by varying the torque transmitted). Figure 11 shows the result. A linear relation is seen between $\Psi$ and $\lambda$, different for driven exit and driver entry but independent of tight side tension.

The effects of belt tooth shape changes on resistance to tooth root cracking may be assessed by studying the sensitivity of $\Psi$ to the design change. Figure 12 shows the 

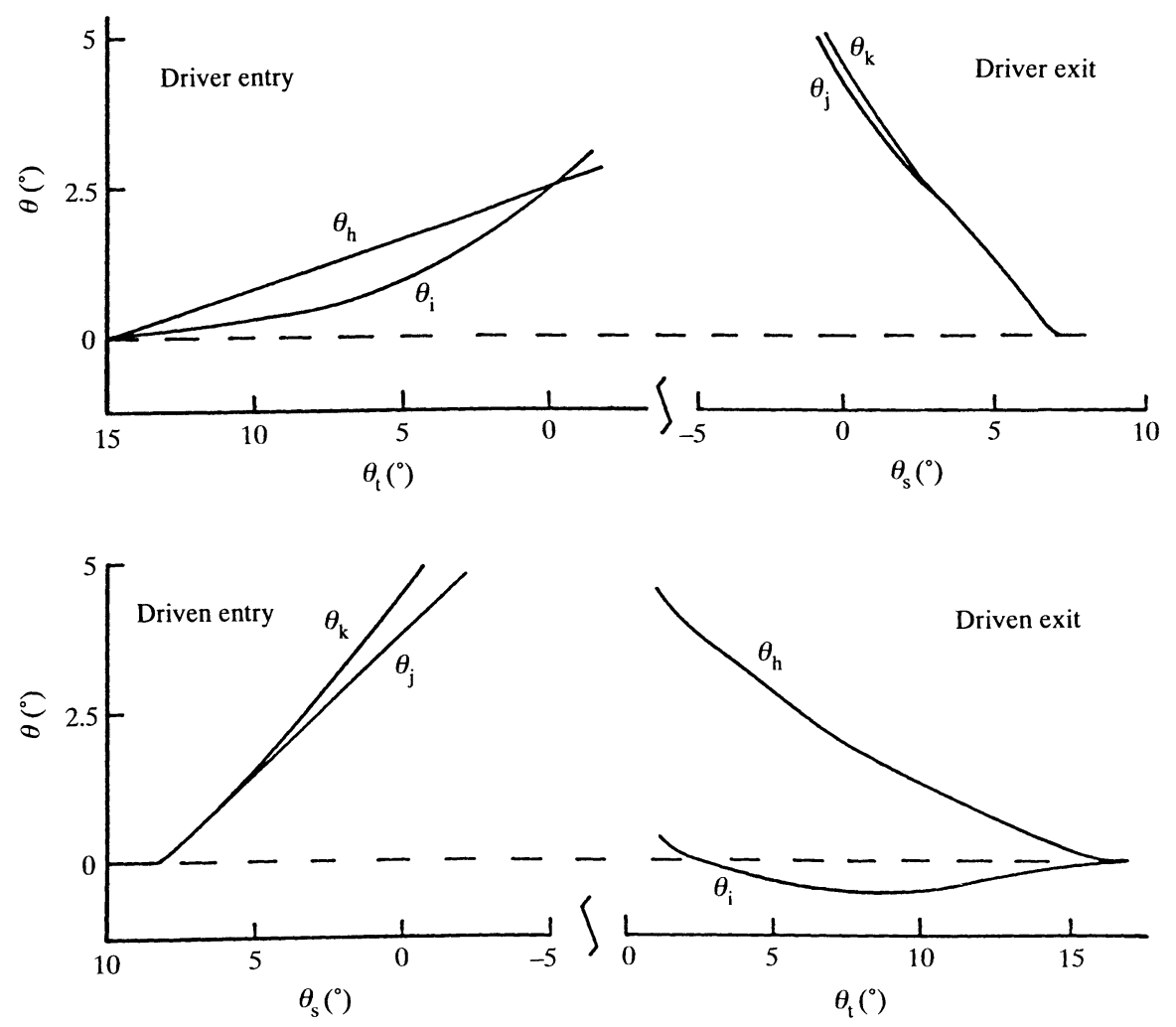

Fig. 8 Calculated hinge angles, conditions as Fig. 7

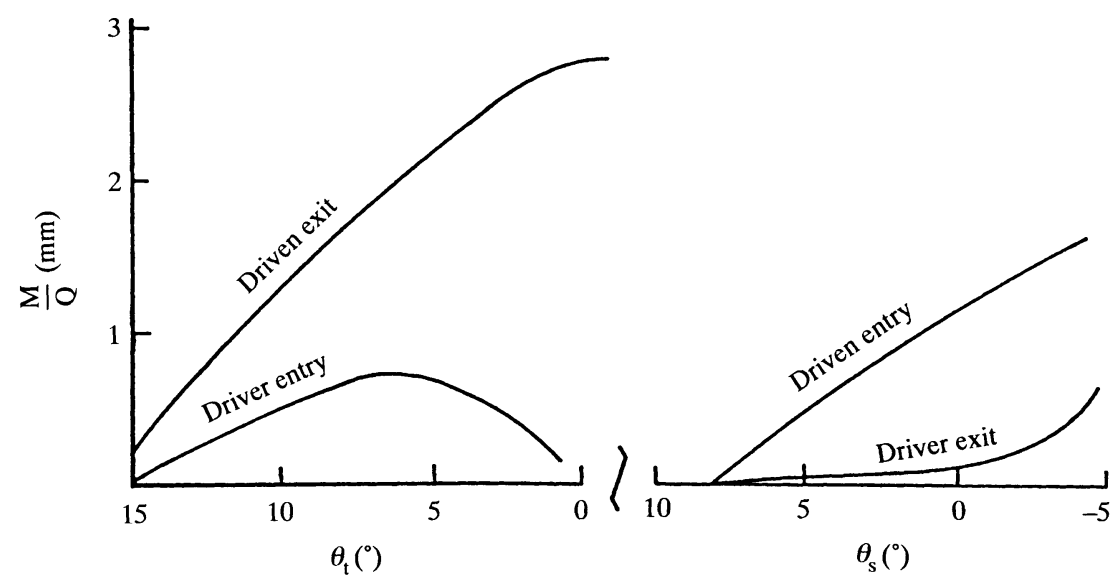

Fig. 9 Calculated tooth bending moments, conditions as Fig. 7

changed relations between $\Psi$ and $\lambda$ caused by changing the pitch line differential. The solid lines are copied from Fig. 11. The solid symbols show the increased $\Psi$ from doubling the pitch line differential and the open symbols show the reduced $\Psi$ by halving the pitch line differential. Figure 13 shows the effect of changing the belt tooth and pulley groove profiles from one type to another as illustrated in Appendix 2, while keeping all other properties constant. The solid lines are again copied from Fig. 11 (profile (a) in Fig. 16, see Appendix 2). The solid symbols show a significantly reduced $\Psi$ for profile (b) in driven exit conditions, while the open symbols show almost no difference at driver entry.

The effects of belt material property changes may also be studied, but some care must be taken. Consider for example the effect of changing the tooth stiffness. If this were achieved by changing the tooth cover material, it is most likely that the material resistance to tooth root cracking (of the cover) would be changed and a mechanical analysis alone would not give guidance of expected life 


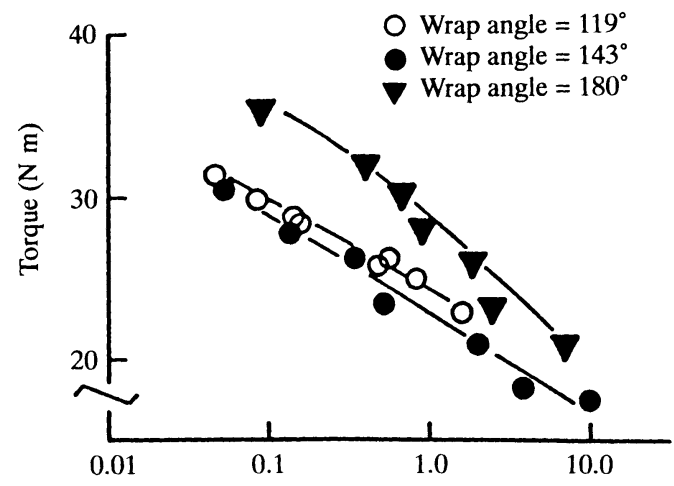

(a)

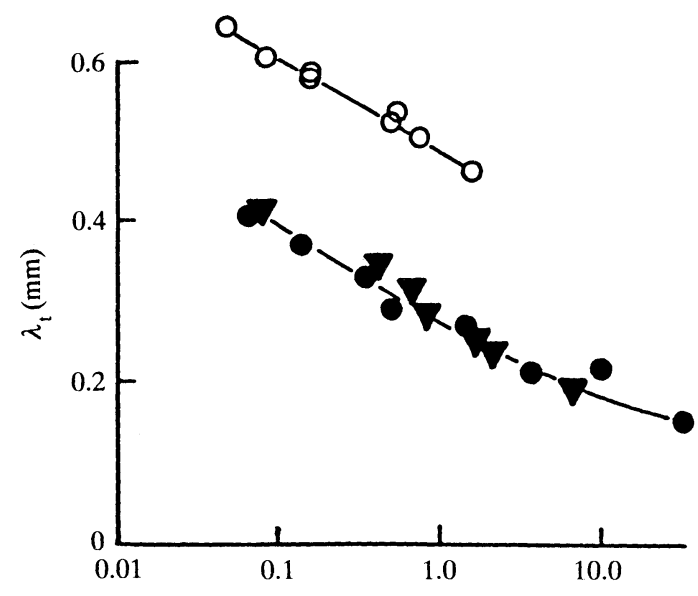

(b)

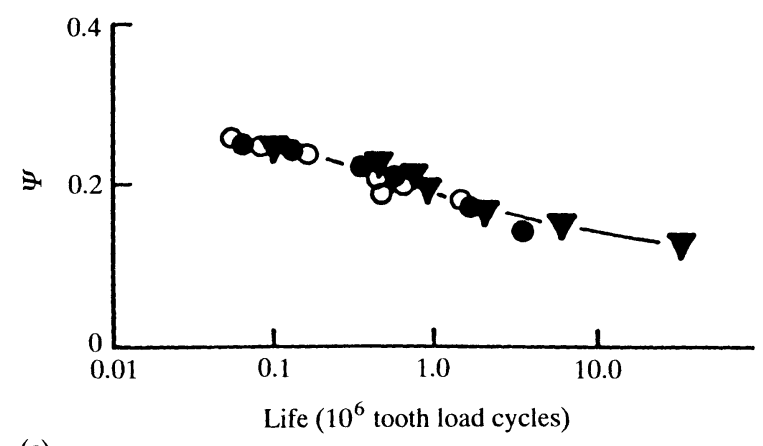

(c)

Fig. 10 Tooth root cracking life comparisons on a basis (a) of torque, (b) of tooth deflection and (c) of effective strain $\Psi$

changes. If, however, stiffness were changed by changing the tooth elastomer, keeping the cover the same, then changes in $\Psi$ might be expected to mirror changes in life. There is still one other complication to consider. Stiffening a tooth will increase the moment on a tooth during meshing/unmeshing but it will also reduce the tooth deflection. Because stiffening has two opposing effects, it is better, rather than investigating how the relation between $\Psi$ and $\lambda$ is changed by stiffening a tooth, to study directly how $\Psi$ varies with tooth stiffness in constant torque

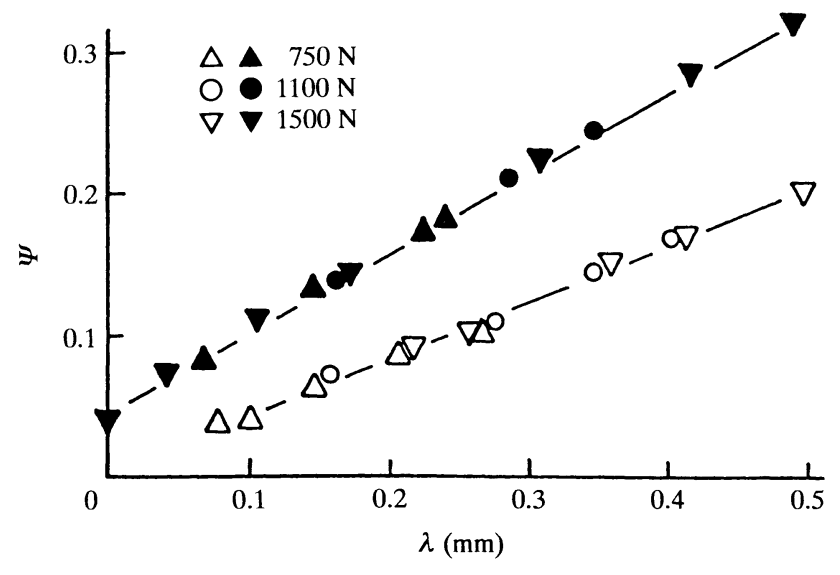

Fig. 11 Dependence of effective strain $\Psi$ on tooth deflection and belt tension of 750, 1100 and $1500 \mathrm{~N}$. Open symbols represent driving and solid symbols represent driven pulleys (belt properties as Table 1 with $P_{\mathrm{p}}-P_{\mathrm{b}}=0.012 \mathrm{~mm}$ )

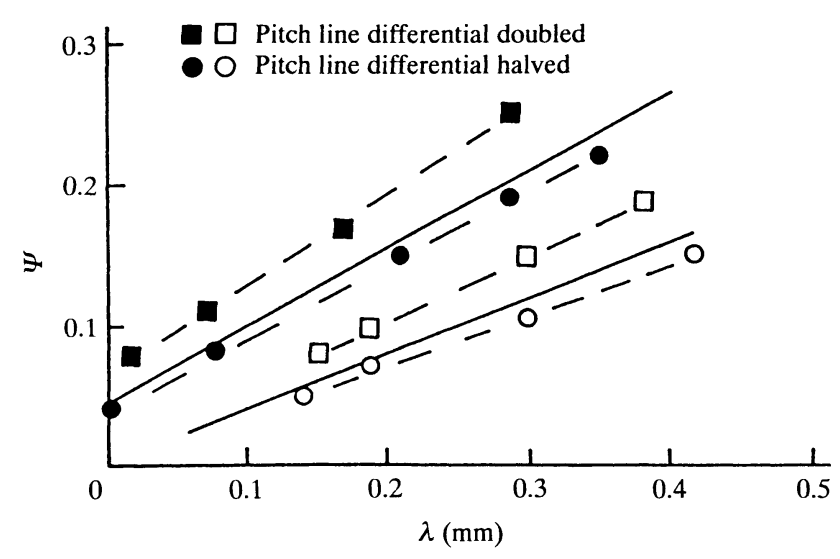

Fig. 12 The effect of doubling and halving pitch line differential on the relationship shown in Fig. 11 (solid line); data calculated at $1100 \mathrm{~N}$

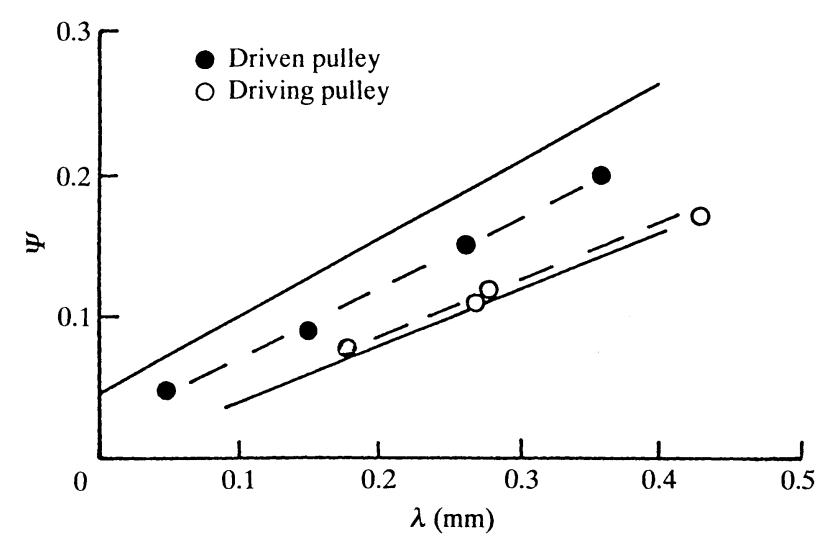

Fig. 13 The effect of changing belt and pulley profile on the relationship shown in Fig. 11 (solid line); data calculated at $1100 \mathrm{~N}$ 


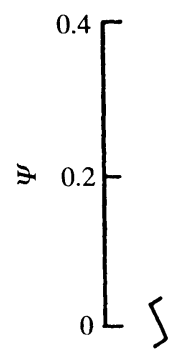

(a)

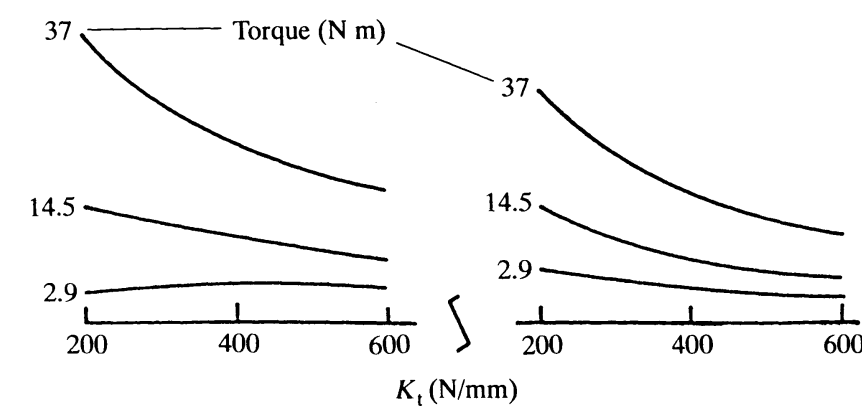

(b)

Fig. 14 The influence of $K_{\mathrm{t}}$ on $\Psi$ at three torque levels, on (a) a driven and (b) a driver pulley, total tension $1500 \mathrm{~N}$

transmission conditions. Figure 14 shows the variation of $\Psi$ with $K_{\mathrm{t}}$ at three different torque levels, all at a total belt tension of $1500 \mathrm{~N}$, (a) on a driven and (b) on a driving pulley. In both cases, increased tooth stiffness leads to reduced $\Psi$.

Similarly, friction may have opposing effects on root cracking. At large belt tensions, when the belt pitch may be longer than the pulley pitch, increasing friction will result in more torque being carried by the belt lands on a driving pulley, and a reduction of tooth load, while on a driven pulley high friction will increase tooth load. This effect is reversed at low belt tensions, when belt pitch is less than pulley pitch. Whatever the tension, belt moments at driven exit are increased by high friction and are reduced at driver entry. So the influence of friction on $\Psi$ is studied here in a similar manner to that of tooth stiffness. In Fig. 15, the influence of friction coefficient on $\Psi$ at constant total tension and torque transmission is shown (a) at a total tension of $1500 \mathrm{~N}$ (when the stretched pitch of the belt is greater than the pulley pitch) and (b) at a total tension of $700 \mathrm{~N}$ (when the stretched belt pitch is mostly less than the pulley pitch). The solid lines show the detrimental effect of increasing friction on driven exit $\Psi$ values. The dashed lines show the beneficial effects at driver entry. The effects at driven exit are more severe than at driver entry.

\section{DISCUSSION}

A mechanical model of partial meshing has been developed that predicts how bending moments develop in both driving entry and driven exit conditions. When belt life is limited by tooth root cracking, a single life law is obtained for both driving and driven failures when life is expressed as a function of effective strain, a sum of loading and bending strains (Fig. 10c). This is an improvement on previous modelling which sought to relate lives to maximum tooth deflections, ignoring entry and exit effects (Fig. 10b). However, it is partially empirical. The effective strain, although dimensionally sound, adds together what has been interpreted as a shear strain and a tensile (bending) strain. A more detailed analysis, for example using finite elements, is needed to describe fully the complex conditions at the tooth root. Be that as it may, the new analysis shows a one-to-one relation between effective strain $\Psi$ [equation (17)] and tooth deflection, more severe at driven exit than driver entry, but independent of belt tension level. A reduction of $\approx 0.05$ in $\Psi$ results in a ten-fold increase in life when tooth root cracking is the cause of failure.

Although the partial meshing analysis has given a unifying measure of root strain, its predictions of force build-up during partial meshing do not agree quantitatively

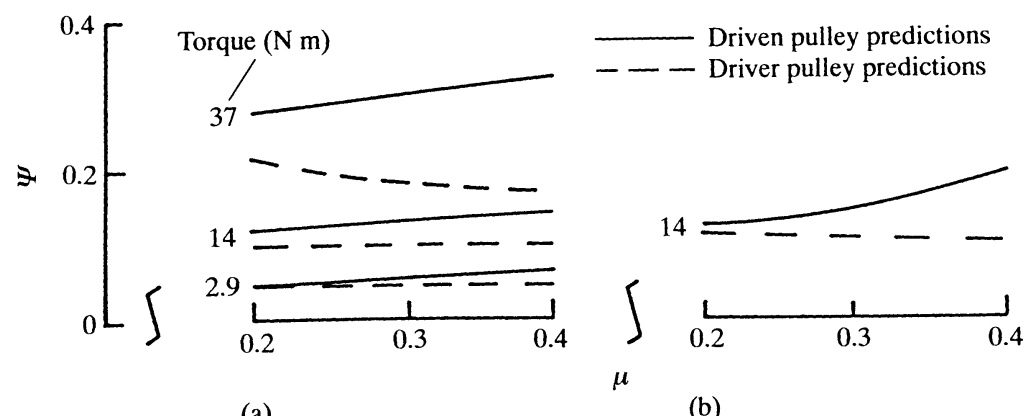

Fig. 15 The influence of sliding friction coefficient on $\Psi$ at three torque levels, at a total tension of (a) $1500 \mathrm{~N}$ and (b) $700 \mathrm{~N}$ 
with experiments, although qualititive patterns of variation can be seen (Fig. 7). The assumption of a belt tooth that maintains a straight back during meshing and is joined to the belt lands by frictionless hinges (Fig. 3) is obviously an over-simplification. It is also an over-constraint to insist that at entry and exit to a pulley only one tooth can be in partial mesh. For all these reasons, work is continuing both to improve the model, relaxing some of its constraints, and to develop alternative, finite element models of partial meshing, against which to calibrate the improvements.

Previous work (6) had concluded that the stiffer a tooth, the better, as far as resistance to tooth root cracking is concerned. The present work confirms this (Fig. 14), and predicts that increasing tooth stiffness is more valuable the higher is the torque. Increasing $K_{\mathrm{t}}$ from 300 to $400 \mathrm{~N} / \mathrm{mm}$ (for a $20 \mathrm{~mm}$ wide belt) typically reduces $\Psi$ by between 0.02 and 0.05 which would increase life from two- to tenfold. The present work also confirms the importance of keeping the pitch line differential small. Figure 12 combined with Fig. 10c predicts that doubling the pitch line differential would cause a ten-fold life reduction. Likewise, the belt profile in Fig. $16 \mathrm{~b}$ is predicted to be ten times more resistant to driven exit tooth root cracking failure than that in Fig. 16a (Fig. 13 with Fig. 10c), but to give no benefit if failure originates at driver entry. Finally the theory predicts that increasing sliding friction has an adverse effect on a driven pulley and a beneficial effect on a driver pulley although at the level of friction coefficient of 0.2 common in practice, the effect is not large for practical levels of torque transmission. All these predictions are based on tooth root failure observations that have been made in laboratory tests, where cracking started with failure of the cover: more complicated situations may arise in service conditions.

\section{CONCLUSION}

A model of timing belt torque transmission has been developed that takes into account the mechanics of partially meshing belt teeth at entry to and exit from driving and driven pulleys. Its entry and exit force predictions have been found to be qualitatively but not quantitatively in agreement with experiment, perhaps because of oversimplifying assumptions and constraints. Nevertheless, it predicts that at entry to a driving pulley bending moments are created that are very different from those at exit from a driven pulley. When belts fail by tooth root cracking, their lives correlate with a measure of strain that combines the effects of full mesh loading and partial mesh bending. When the theory is used to predict the effect of belt design changes on resistance to tooth root cracking, it concludes that increased tooth stiffness should increase belt life and that increased pitch line differential should reduce life. It also shows differences between one belt tooth profile and another.

\section{ACKNOWLEDGEMENTS}

The work has been carried out as part of a programme on belt mechanics supported by the UK Engineering and Physical Sciences Research Council (EPSRC), Dayco PTI SpA, du Pont de Nemours and other industrial companies. One of the authors (M.H.H.) wishes to acknowledge the Iranian government for a scholarship.

\section{REFERENCES}

1 Neale, M. J. (Ed.) Drives and Seals, a Tribology Handbook, 1994, Sec. 1 (Butterworth Heinemann, Oxford).

2 Murakami, Y. and Watanabe, M. Study of belt strength through an examination of strain on belt cords. SAE paper $880415,1988$.

3 Iizuka, H., Watanabe, M. and Mashimo, S. Observations of fatigue failure in synchronous belts. Fatigue Fracture Engng Mater. Structures, 1994, 17, 783-790.

4 Dalgarno, K. W., Day, A. J. and Childs, T. H. C. Synchronous belt materials and belt life correlation. Proc. Instn Mech. Engrs, Part D, 1994, 208 (D1), 37-48.

5 Childs, T. H. C., Parker, I. K., Day, A. J., Coutsoucos, A. and Dalgarno, K. W. Tooth loading and life of automotive timing belts. Proceedings of 17th Leeds-Lyon Symposium on Tribology, 1991, pp. 341-348 (Elsevier, Amsterdam).

6 Koyama, T., Kagotani, M., Shibata, T., Sato, S. and Hoshiro, T. A study on strength of toothed belt-3rd report. Bull. JSME, 1979, 22, 988-993.

7 Childs, T. H. C., Coutsoucos, A., Dalgarno, K. W., Day, A. J. and Parker, I. K. Life prediction of automotive timing belts. Proceedings of International Conference on Motion and Power Transmission, 1991, pp. 376-381 (Japanese Society of Mechanical Engineers, Tokyo).

8 Johnson, K. L. Contact Mechanics, 1st edition, 1985, Sec. 4.3 (Cambridge University Press, Cambridge).

9 National Algorithm Library (NAG) routine C05NBF.

\section{APPENDIX 1}

\section{Belt cord stretching in partial meshing}

The cord tension in the belt land (Fig. 3a) varies from the value $T_{1}$ at $\mathrm{F}$ to a value $T_{\mathrm{G}}$ at $\mathrm{G}$ and is then constant over the length GH. An adaptation of the full mesh modelling [equations (3) and (4)], gives $T_{\mathrm{G}}$ as

$$
T_{\mathrm{G}}=T_{1} \exp \left(\delta \mu \theta_{\mathrm{f}}\right)
$$

A further adaptation [equation (9)] gives the stretch of the belt land $\mathrm{d} l$ as

$$
\mathrm{d} l=\frac{P_{\mathrm{p}}}{P_{\mathrm{b}} K_{\mathrm{b}}}\left\{\frac{\theta_{\mathrm{l}}-\theta_{\mathrm{f}}}{\theta_{\mathrm{p}}} T_{\mathrm{G}}+\frac{T_{\mathrm{G}} \delta}{\mu \theta_{\mathrm{p}}}\left[1-\exp \left(-\delta \mu \theta_{\mathrm{f}}\right)\right]\right\}
$$

If the unstretched belt land length is $l$, and recognizing that the loading of the first tooth in full mesh causes the partially meshed land to be out of register with the pulley land by $\lambda_{1}$, 

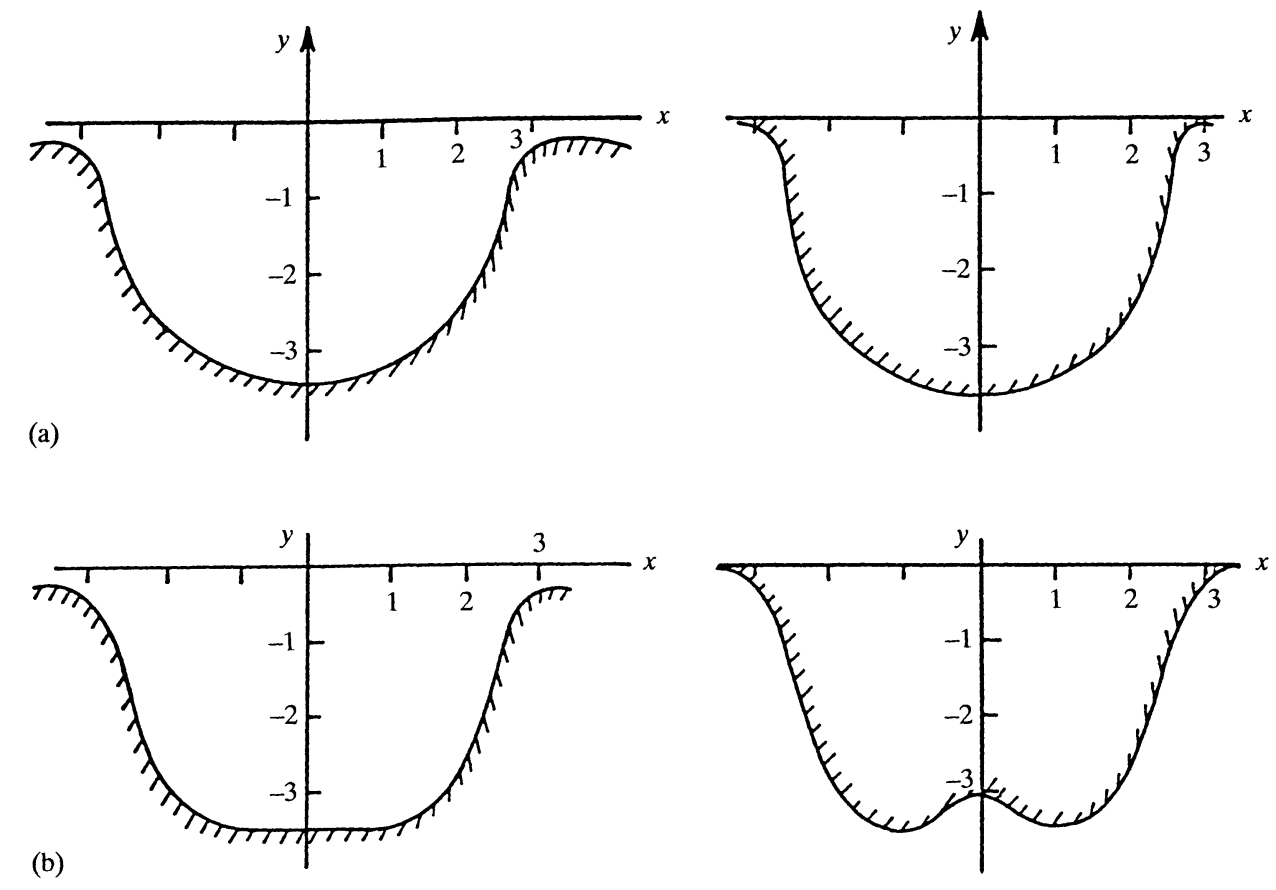

Fig. 16 Parts (a) and (b) show the two commercial curvilinear pulley and tooth profiles studied in this paper (dimensions in $\mathrm{mm}$ )

$$
l_{\mathrm{GH}}=l+\mathrm{d} l-\lambda_{l}-R_{\mathrm{c}} \theta_{\mathrm{f}}
$$

The cord tension above the tooth varies from $T_{\mathrm{G}}$ at $\mathrm{H}$ to the tight side tension $T_{\mathrm{t}}$ at $\mathrm{I}$. If this variation is assumed to be linear, the stretch of the cord from $\mathrm{H}$ to I can be calculated. Because the length from $\mathrm{H}$ to the tooth centre $\mathrm{O}_{t}$ is of interest, the expression used for $l_{\mathrm{HI}}$ in equation (10) is

$$
l_{\mathrm{HI}}=l_{\text {tooth }}+\frac{P_{\mathrm{p}}}{P_{\mathrm{b}} K_{\mathrm{b}}}\left[\frac{\theta_{\mathrm{g}}}{\theta_{\mathrm{p}}} \frac{\left(1.5 T_{\mathrm{g}}+0.5 T_{\mathrm{t}}\right)}{2}\right]
$$

where $l_{\text {tooth }}$ is the unstretched length of the cord above the tooth. Similar equations may be developed for the slack side partially meshed contact.

In adapting the full mesh equations as above, there is an implicit assumption, in locating the position of the hinge $\mathrm{H}$, that there is no backlash of the belt tooth in the pulley groove.

\section{APPENDIX 2}

\section{Partial meshing belt tooth/pulley groove geometry relations}

In this work, the pulley groove and belt tooth profiles are defined numerically by the coordinate data sets $\left(x_{\mathrm{p}}^{\prime}, y_{\mathrm{p}}^{\prime}\right)_{i}$, $\left(x_{\mathrm{b}}^{\prime}, y_{\mathrm{b}}^{\prime}\right)_{i}, i=1$ to $n$, referred to the coordinate systems
$\mathrm{O} x_{\mathrm{p}}^{\prime}, \mathrm{O} y_{\mathrm{p}}^{\prime} ; \mathrm{O} x_{\mathrm{b}}^{\prime}, \mathrm{O} y_{\mathrm{b}}^{\prime}$ as illustrated in Fig. 16. The transformation to the coordinate system $\mathrm{O} x, \mathrm{O} y$ (Fig. 3) is achieved as follows for the tight side, with similar expressions for the slack side $\left(\theta_{\mathrm{v}}\right.$ replacing $\left.\theta_{\mathrm{u}}\right)$ :

$$
\begin{aligned}
& x_{\mathrm{p}, i}=x_{\mathrm{p}, i}^{\prime} \\
& y_{\mathrm{p}, i}=y_{\mathrm{p}, i}^{\prime}-\mathrm{d} R_{\mathrm{p}} \\
& x_{\mathrm{b}, i}=x_{\mathrm{O}_{\mathrm{t}}}+x_{\mathrm{b}, i}^{\prime} \cos \theta_{\mathrm{u}}-\left(y_{\mathrm{b}, i}^{\prime}-\mathrm{d} R_{\mathrm{p}}\right) \sin \theta_{\mathrm{u}} \\
& y_{\mathrm{b}, i}=y_{\mathrm{O}_{\mathrm{t}}}+x_{\mathrm{b}, i}^{\prime} \sin \theta_{\mathrm{u}}+\left(y_{\mathrm{b}, i}^{\prime}-\mathrm{d} R_{\mathrm{p}}\right) \cos \theta_{\mathrm{u}}
\end{aligned}
$$

The profiles are regarded as $n-1$ linear segments, joining points $i$ and $i+1, i=1$ to $n-1$. A tooth/pulley interference assessment is carried out for every pulley surface segment. The normal to the pulley segment is constructed, passing through the point $\left[\left(x_{\mathrm{p}, i}+x_{\mathrm{p}, i+1}\right) / 2\right.$, $\left.\left.\left(y_{\mathrm{p}, i}+y_{\mathrm{p}, i+1}\right) / 2\right)\right]$, with gradient $-\left(x_{\mathrm{p}, i+1}-x_{\mathrm{p}, i}\right) /$ $\left(y_{\mathrm{p}, i+1}-y_{\mathrm{p}, i}\right)$. It is checked which belt segment the normal intersects, what is the distance between the pulley and belt segment and whether the distance is a gap or an overlap. If the distance $l_{i}$ is an overlap, the area $\delta A_{i}$ of the overlap is calculated from

$$
\delta A_{i}=l_{i} \sqrt{ }\left[\left(x_{\mathrm{p}, i+1}-\mathrm{x}_{\mathrm{p}, i}\right)^{2}+\left(\mathrm{y}_{\mathrm{p}, i+1}-\mathrm{y}_{\mathrm{p}, i}\right)^{2}\right]
$$

